\title{
EDUCAÇÃO E TECNOCIÊNCIA NO BRASIL CONTEMPORÂNEO: PERSPECTIVAS INVESTIGATIVAS AOS ESTUDOS CURRICULARES
}

\begin{abstract}
RESUMO: O presente texto apresenta um breve estudo acerca das relações entre educação e tecnociência no Brasil contemporâneo. Inicialmente, foram examinadas as condições culturais que operam na inserção dessas temáticas nas práticas contemporâneas em educação. A seguir, estabeleceu-se um mapeamento das principais tendências investigativas na área, tomando como material analítico dissertações e teses produzidas no país no período entre 2004 e 2009. Três tendências investigativas mostraram-se predominantes: práticas escolares, políticas curriculares e tecnológicas e dinâmicas culturais e sociabilidades contemporâneas. Finalmente, procurou-se estabelecer algumas perspectivas investigativas no campo, bem como alguns pressupostos investigativos para os estudos dos currículos escolares e suas políticas na contemporaneidade.

Palavras-chave: Educação, Tecnociência, Estudos Curriculares.
\end{abstract}

Roberto Rafael Dias da Silva*

EDUCATION AND TECHNOSCIENCE IN CONTEMPORARY BRAZIL: INVESTIGATIVE PERSPECTIVE TO CURRICULUM STUDIES

ABSTRACT: This paper presents a brief study of the relationship between education and Technoscience in contemporary Brazil. Initially, we examine the cultural conditions that operate in the insertion of these themes in contemporary practices in education. Next, we aim to establish a mapping of the main investigative trends in the area, using as a corpus dissertations and theses produced in Brazil between 2004 and 2009. Three investigative tendencies are prevalent: school practices, curricular and technology policies, and contemporary cultural dynamics and sociability. Finally, we seek to establish some investigative perspective in the field, as well as some investigative assumptions for the studies of school curricula and their contemporary policies.

Keywords: Education, Technoscience, Curriculum Studies.

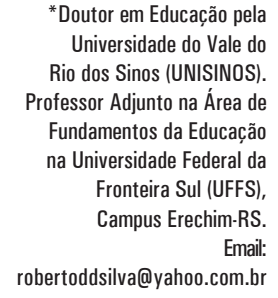

${ }^{*}$ Doutor em Educação pela Universidade do Vale do Rio dos Sinos (UNISINOS). Professor Adjunto na Área de Fundamentos da Educação na Universidade Federal da Fronteira Sul (UFFS), Campus Erechim-RS. Email:

robertoddsilva@yahoo.com.br 


\section{INTRODUCุ̃̃O}

A questão da ciência e da tecnologia enquanto temáticas educacionais despertou o interesse para a realização desta elaboração investigativa. Consideramos instigante pensar nos modos pelos quais as questões da ciência e da tecnologia começam a adquirir relevância e produtividade na educação brasileira, sobretudo com as reformas curriculares desencadeadas desde meados dos anos 1990. Entretanto, para fins introdutórios, interessa destacar que o presente texto não pretende constituir-se como um estudo da constituição da ciência e da tecnologia em si mesmas, mas interessa-nos pensar em suas interfaces, sobretudo no que tange as suas aproximações com os currículos escolares do Ensino Médio no Brasil contemporâneo. Neste estudo, então, pensar acerca dessa perspectiva implica em examinar as condições culturais que operam para a inserção dessas temáticas nas práticas contemporâneas em educação, assim como estabelecer um mapeamento das principais tendências investigativas nessa área no Brasil contemporâneo.

Seguindo as reflexões de Latour (2000), a escolha de uma porta de entrada para essa temática, multiplicada no jogo de relações do capitalismo contemporâneo, não se apresenta como uma tarefa simples. Implica em um conjunto de escolhas (teóricas e metodológicas) acerca de quais caminhos percorrer. Neste estudo, gostaríamos de destacar algumas balizas metodológicas que orientaram nossas primeiras entradas no campo. $\mathrm{O}$ uso de tais balizas foi inspirado nas descrições etnográficas de laboratórios, produzidas por Latour (2000). Desde essas condições, orientamos nossa entrada no campo da ciência e da tecnologia enquanto temáticas educacionais, mobilizando dois pressupostos. Em primeiro lugar, optamos em dirigir um olhar para a ciência em ação, ou seja, para as práticas científicas e tecnológicas que são visibilizadas nas sociedades contemporâneas. Optar pela ciência em ação deriva-se da necessidade de abordar essas temáticas antes que elas se convertam em "caixas-pretas". "A expressão caixa-preta é usada em cibernética sempre que uma máquina ou um conjunto de comandos se revela complexo demais" (LATOUR, 2000, p. 14). Esse primeiro pressuposto articula-se à possibilidade de um olhar pragmatizado acerca das relações entre ciência e sociedade, visto que estas se dão nas práticas.

Em segundo lugar, procuramos tomar as práticas científicas como heterogêneas, ou seja, entendê-las como produzidas em dinâmicas culturais múltiplas e instáveis. Em aproximação com o que vem sendo chamado de "Estudos Culturais da Ciência" (WORTMANN; VEIGA-NETO, 2001), entendemos que é pouco produtivo procurar fixar significações a priori à materialidade das práticas científicas, uma vez que há uma variabilidade de atividades que interferem na produção contemporânea da ciência e da tecnologia. Com esses dois pressupostos, movemo-nos com o entendimento de que a ciência e a tecnologia são práticas (culturais e sociais) heterogêneas. Assim, não procuramos lançar mão de nenhuma teoria ou filosofia da ciência e da tecnologia que orientasse nossas incursões pela temática. Fez-se produtivo (e também útil) pensar tais noções enquanto práticas 
regidas por racionalidades políticas, inscritas em diversos regimes de poder e de saber, seguindo um itinerário metodológico inspirado nos estudos foucaultianos do final da década de 1970 (FOUCAULT, 2008a; FOUCAULT, 2008b).

A partir desse conjunto de argumentos, organizamos o presente texto em três seções. Na primeira, além de situarmos os entendimentos de tecnociência que estamos mobilizando, discutimos as condições culturais de sua emergência como pauta educacional contemporânea. Na segunda seção, estabelecemos uma revisão da literatura brasileira entre os anos de 2004 e 2010, mapeando suas principais tendências, assim como evidenciando as principais perspectivas desenvolvidas na área. Por fim, apresentamos algumas ressonâncias dessa temática nos currículos escolares do Ensino Médio no Brasil, revisando alguns de seus principais documentos normatizadores, de modo a estabelecer algumas perspectivas investigativas no campo, bem como alguns pressupostos investigativos para os estudos dos currículos escolares e suas políticas na contemporaneidade.

\section{SOBRE A TECNOCIÊNCIA: PERSPECTIVAS CULTURAIS E POLÍTICAS}

Ao longo da última década, intensificaram-se os programas de investimentos públicos e privados na área de ciência e tecnologia no Brasil. Acerca disso, vale recordar que a criação de um Ministério que coordena e dinamiza tais políticas no país é recente, sendo inaugurado no ano de 1985. Tais temáticas têm se tornado pauta constante de plataformas políticas, em geral incentivando essas áreas com vistas à consolidação de um desenvolvimento nacional. Ao mesmo tempo, inúmeros estudos apontam, desde os anos 1950, os modos pelos quais a dependência na produção e na distribuição de tecnologia tornaram-se um entrave para esse desenvolvimento (FURTADO, 1987; FERNANDES, 1987). Entretanto, foi a partir do final dos anos 1990 que essas políticas ganharam impulso, não apenas por ações estatais, mas por um amplo investimento privado. Como assinalam os Indicadores Nacionais de Ciência e Tecnologia (MCT, 2008), os totais de investimentos aumentaram em 144,5\% durante essa década, ou seja, somente no período entre 2000 e 2007.

Nesse cenário de significativo crescimento da ciência e da tecnologia no Brasil, importa destacar um conceito emergente sob essas condições: a tecnociência. Avançaremos um pouco nessa discussão para apresentar alguns significados que estamos atribuindo a esse conceito. Assim, mais uma vez, importa destacar que não desejamos fixar um significado a essa expressão ou buscar um conceito final e imutável, mas apresentar alguns usos que julgamos produtivos a esse conceito na contemporaneidade. Partindo de um ponto de vista mais sociológico, estudos como os de Latour (2000), Lenoir (1997), ou mesmo de Postman (1994), têm procurado examinar tal produção. Em um cenário mais filosófico, as discussões de pós-ciência (DIAZ, 2007), ou mesmo de pós-humanidade (MARCHESINI, 2009), também se preocuparam com essa questão. Em nosso país, tendo em 
vista uma abordagem mais contemporânea, as pesquisas de Santos (2005, 2007) e Sibília (2009) deram importantes contribuições para a instauração de algumas dessas problematizações nas universidades brasileiras.

Obviamente, o campo dos interessados na questão não se restringe a essa relação aqui apresentada, nem mesmo detalharemos cada abordagem, apesar de sua indiscutível relevância. Como nosso objetivo está nos usos, trataremos tal descrição de modo diagonal, ou seja, perpassaremos algumas dessas abordagens à medida que derem produtividade ao olhar que pretendemos construir. Diaz (2007), ao tratar a questão com um ponto de vista mais epistemológico, argumenta que a tecnociência é derivada de um novo conjunto de condições que delineiam a produção do conhecimento. Segundo a autora, desde meados do século XX não se fez mais possível a diferenciação entre ciência e técnica, sobretudo desde o entendimento de que a maioria dos avanços científicos eram mobilizados a partir de um aparato técnico, especialmente em relação a questões como o transporte, a saúde, ou mesmo a comunicação. "Mas a partir da invenção dos computadores, a obtenção da fissão nuclear e o desenvolvimento da engenharia genética, para nomear somente alguns exemplos paradigmáticos, torna claro que não existe investigação básica 'incontaminada' de técnica” (DIAZ, 2007, p. 28).

Entretanto, segundo a filósofa, o principal aspecto pelo qual a tecnociência poderia ser compreendida é o modo pelo qual ela é regida. A tecnociência seria regida, em geral, "pelas regras do mercado, a 'pronta-entrega', a obsolescência de seus produtos, o devir da política, a busca de recursos e a maquinaria bélica travestida sob a apressada obsessão de 'seguridade"' (DIAZ, 2007, p. 29). Aqui podemos estabelecer um primeiro modo de compreensão da tecnociência que interessa a esta investigação: suas articulações com o mercado em diferentes nuances.

Por meio de uma abordagem mais sociológica, Bruno Latour (2000) aponta que os atuais modos de produção científica, ao articularem permanentemente ciência e tecnologia, nos conduziriam a pensar na constituição de uma tecnociência. O autor também argumenta que vemos atualmente uma indissociabilidade entre pesquisa básica e tecnológica, uma vez que tanto dentro dos laboratórios, quanto os movimentos fora dos laboratórios (captação de recursos, participação em congressos, etc.), dão condições e produtividade à tecnociência. Ou seja, interna ou externamente à ciência básica, todos são mobilizados pelos arranjos tecnocientíficos, o que, inclusive, não nos permite responder à pergunta: "afinal, quem realmente está fazendo ciência?” (LATOUR, 2000, p. 259).

Partindo da impossibilidade de separar os movimentos de "para dentro ou para fora" das práticas tecnocientíficas, novos elementos passam a integrar seus circuitos de produção: "dinheiro, força de trabalho, instrumentos, objetos novos, argumentos e inovações” (LATOUR, 2000, p. 263). Nesse momento, podemos indicar uma segunda compreensão de tecnociência, que, de certa forma, amplia a primeira: a tecnociência é mobilizada por um conjunto de práticas (internas ou externas à pesquisa básica) que regulam a produção de conhecimento na contemporaneidade. A tecnociência, enfim, pode constituir-se como uma estratégia política que 
articula positivamente a ciência e a tecnologia às dinâmicas do capitalismo atual.

Avançando nessa discussão, ainda precisamos destacar como os modos de produção e os saberes tecnocientíficos não ficam circunscritos a regimes endógenos. A tecnociência, enquanto um regime de práticas, multiplica-se pelos diferentes espaços sociais de nosso tempo, a ponto de até mesmo aquilo que nomeamos como natural ou humano seja colocado sob suspeita (SANTOS, 2005; SIBILIA, 2009; MARCHESINI, 2009). Sob essas condições, a tecnociência passa a constituir-se como um "estado de cultura", assemelhando-se àquilo que Postman (1994) chamou "tecnopólio". "Tecnopólio é um estado da cultura. Também é um estado da mente. Consiste na deificação da tecnologia, o que significa que ele procura sua autorização na tecnologia, encontra sua satisfação na tecnologia e recebe ordens da tecnologia" (POSTMAN, 1994, p. 79).

Ainda que não concordemos totalmente com a argumentação de Postman, é significativo nesse momento reconhecer as formas pelas quais a tecnociência conduz as vidas das pessoas, indicando os melhores modos de experienciar a atualidade. Assim, a tecnociência, os saberes tecnocientíficos, ou ainda o que estamos nomeando provisoriamente de "educação tecnocientífica", produzem efeitos significativos. Enfim, é sob esses entendimentos que mobilizamos o conceito de tecnociência, procurando situar suas interfaces com as lógicas culturais e políticas de nosso tempo. Tomando como ponto de partida essas relações entre tecnociência e cultura, expostas nesta seção, a seguir examinaremos algumas das tendências investigativas mobilizadas nas interfaces entre educação e tecnociência no Brasil contemporâneo.

\section{EDUCAÇÃO E TECNOCIÊNCIA: UMA BREVE REVISÃO}

Acerca das relações entre educação e tecnociência não encontramos estados da arte que façam um inventário amplo e diversificado dessa produção. De maneira a orientar essas inserções no campo, utilizamos dois textos que se propõem a sistematizar algumas tendências investigativas próximas a essa questão. Danigno (2007) expõe as perspectivas contemporâneas desses estudos no âmbito das políticas públicas no Brasil. Vacarezza (1998) faz um movimento semelhante ao diagnosticar a historicidade da questão e suas novas demandas na América Latina.

Procurando compreender os modos pelos quais as pesquisas têm apresentado as questões da ciência e da tecnologia, Danigno (2007) apresentou quatro perfis de entendimento que não apenas teriam complementaridades, como também denotariam os pressupostos políticos dessas pesquisas. O pesquisador, que é uma referência na área de política científica e tecnológica no Brasil, indica o instrumentalismo, o determinismo, o substantivismo e a adequação sociotécnica como perfis de entendimento ou "tipos científico-tecnológicos" (DANIGNO, 2007, p.6). O instrumentalismo combina perspectivas do controle humano da tecnologia e da neutralidade de valores, ao mesmo tempo em que entende a tecnologia como uma ferramenta humana por meio de métodos que "asseguram à ciência atributos de 
verdade e à tecnologia de eficiência" (DANIGNO, 2007, p.6). Conforme Danigno, o instrumentalismo é evidenciado nos otimismos liberal e positivista, marcados pela fé no progresso através da ciência. Um outro perfil seria o determinismo, típico, como aponta o autor, do otimismo da esquerda marxista tradicional. Esse entendimento posiciona as relações entre sociedade e tecnologia no impulso de uma "força que molda e empurra inexoravelmente a sociedade mediante exigências de eficiência e progresso que ela própria estabelece" (DANIGNO, 2007, p. 7).

O terceiro modo de entendimento apontado por Danigno é o substantivismo. Esta concepção aborda de maneira crítica os valores da tecnologia capitalista, como "a eficiência, o controle e o poder" (DANIGNO, 2007, p. 8). Ao compartilhar aspectos com a Escola de Frankfurt, as perspectivas substantivistas apontam que esse modelo de ciência e tecnologia capitalistas "não poderia ser usado para viabilizar propósitos de indivíduos ou grupos sociais que patrocinem outros valores e interesses" (DANIGNO, 2007, p. 8), ou seja, esse modelo torna-se ideologicamente comprometido. O quarto modo de conceber a ciência e a tecnologia na atualidade é apontado como adequação sociotécnica. Tal visão Compartilha muitos aspectos com as abordagens anteriores, entendendo a ciência e a tecnologia "como passível de ser controlada pelos grupos sociais (negando sua autonomia) e como portadora de valores" (DANIGNO, 2007, p. 8). Entretanto, o que diferencia esta concepção é que ela ainda concebe a C\&T como "uma promessa de liberdade" (DANIGNO, 2007, p. 8), isto é, aceita suas críticas e seus limites, mas acredita no "reprojetamento das tecnologias atualmente disponíveis" (DANIGNO, 2007, p. 9), vinculando-as a projetos alternativos de sociedade.

Um outro levantamento do campo foi realizado por Vacarezza (1998). $O$ pesquisador argentino realiza em seu artigo um levantamento das condições da ciência e da tecnologia na América Latina, assim como descreve e historiciza o pensamento latino-americano sobre essas temáticas. A condição histórica das políticas deste setor é caracterizada desde os anos 1950, década em que essa temática começa a entrar na pauta das políticas públicas: pelos baixos índices de investimento, desníveis regionais nos investimentos e pela contínua dependência do Estado. Desde a década de 1950, conforme evidencia o sociólogo, há um forte processo de institucionalização, "tanto da investigação científica e tecnológica como dos distintos mecanismos de desenvolvimento do setor" (VACAREZZA, 1998, p. 17). Tal condição se consolidará durante as três décadas seguintes, visto que é possível notar um esforço quase exclusivo dos Estados para provocar as dinâmicas de inovação do conhecimento e da economia.

Apenas no final dos anos 1980 que a situação começou a alterar-se. Acerca disso, duas questões, conforme Vacarezza, tornaram-se centrais: “a) a mudança no papel do Estado, isto é, a diminuição de suas funções reguladoras e produtivas; b) a abertura das economias latino-americanas ao comércio e à competitividade internacionais" (VACAREZZA, 1998, p. 18). A ênfase na competitividade não apenas implicou na alteração do papel dos Estados nacionais, como deu condições para a emergência de um novo ator, ainda pouco envolvido nessas temáticas no ce- 
nário dessa região: a iniciativa privada. Essas modificações foram levadas ao limite nas décadas seguintes, espalhando por inúmeras áreas, a fazendo do conhecimento científico e tecnológico "setores de aplicação" (VACAREZZA, 1998, p.19).

Esses deslocamentos no campo das políticas do setor trouxeram novas perspectivas para os campos de estudo ligados à ciência, à tecnologia e à sociedade. O pensamento latino-americano sobre essas questões, da década de 1950 ao início dos anos 1980, estava muito vinculado às noções de atraso tecnológico, dependência, transferência de tecnologia ou mesmo de revolução política. Com as alterações descritas nos anos de 1990, modificaram-se e complexificaram-se as investigações no setor. As pesquisas tornaram-se mais acadêmicas e menos políticas, o que ocasionou, ainda segundo o sociólogo, uma maior especialização e profissionalização. Essa situação mobilizou alguns desvios na pesquisa e na produção política da área, tais como: o Estado como um gestor de demandas, forte aproximação com estratégias de mercado e o desenvolvimento nacional voltado para a competitividade internacional. Como tendências na pesquisa no campo, Vacarezza aponta a análise de políticas científicas e tecnológicas, a gestão das tecnologias, os processos de inovação, a vinculação entre ciência e produção, a prospectiva tecnológica e os impactos sociais. Como a ênfase contemporânea desses estudos está na administração e na gestão, o sociólogo indica que a principal necessidade das investigações está em tratar o campo da sociedade, historicizar e examinar interdisciplinarmente a sociedade "como âmbito de desenvolvimento dos fenômenos e como sujeito coletivo" (VACAREZZA, 1998, p.38).

A partir das condições acima descritas, procuramos cartografar algumas das principais tendências investigativas nessa área no Brasil. Imediatamente notamos a predominância de estudos qualitativos, ocorrendo uma preferência pelos estudos de caso, análises documentais e pesquisas participantes. No que se refere ao foco teórico dessas investigações, notamos uma diversidade de perspectivas, assim como a incorporação de múltiplos olhares teóricos sobre a questão. Essa diversidade teórica permite observar os modos pelos quais essa temática tem sido relevante nos debates educacionais contemporâneos, e também como tem participado das preocupações sociais do período analisado. Podemos notar, sob diferentes possibilidades, estudos antropológicos, históricos, políticos, sociológico-filosóficos, didáticos e curriculares.

O mapeamento dessa produção em educação-ciência-tecnologia no Brasil, tendo por base 47 pesquisas (teses e dissertações), indicou que esse campo investigativo tem sido bastante fértil no decorrer do período analisado. Diferentes programas de pós-graduação têm apresentado produtividade nessa temática, não ficando circunscrita à Educação. Áreas como Política Tecnológica, Informática, Engenharia Mecânica, Educação Científica e Tecnológica, Letras, Ciências Sociais, Ensino de Física, Biociências e Saúde, Sociologia, Comunicação Social, dentre outras, têm produzido investigações significativas acerca da temática. Ainda é preciso referir que as teorizações mais evidenciadas são a teoria crítica, os estudos CTS e os estudos sociais da ciência e da tecnologia (sobretudo nas políticas tecnológicas). 
De maneira a operarmos analiticamente sobre essas pesquisas, assim como para agruparmos estudos relevantes na área, conseguimos visualizar que esses estudos apresentam pelo menos três ênfases: as práticas escolares (incluindo a formação de professores), as políticas públicas (sejam curriculares ou tecnológicas) e as dinâmicas culturais (associadas ou não à produção das sociabilidades contemporâneas).

Gráfico 1: Ênfase Temática

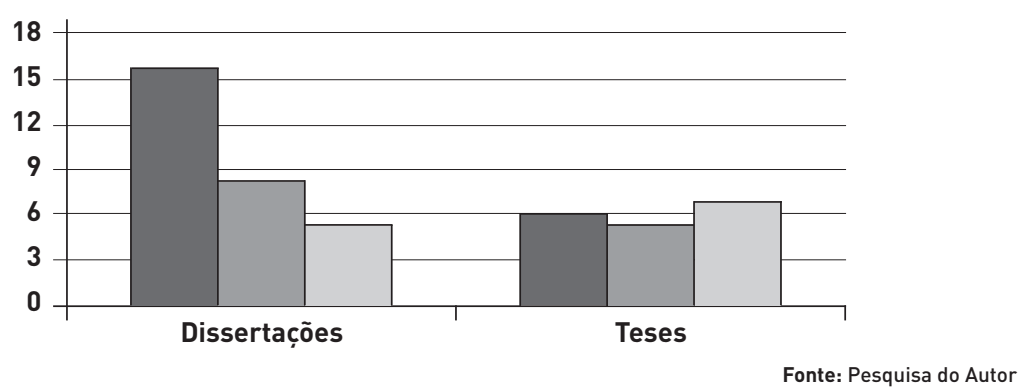

Ao estabelecermos essas três ênfases, procuramos tornar visíveis as características e as condições que têm perpassado a produção investigativa sobre essa temática. Para isso, nos aproximaremos de algumas pesquisas que não apenas trazem contribuições para o estudo da questão, como permitem com que consigamos descrever os modos pelos quais estabelecemos algumas compreensões do campo. De maneira a organizarmos essa apresentação, subdividiremos, de agora em diante, a caracterização das três ênfases temáticas produzidas.

Enquanto práticas escolares consideramos aqueles estudos que se centravam na problematização entre ciência, tecnologia e educação, tomando as possibilidades de educação escolarizada como espaços de mediação. Nesse sentido, consideramos como práticas escolares os estudos que enfatizavam situações didáticas, situações diversificadas de aprendizagem, formação de professores e educação a distância. Nesses estudos, predominaram aqueles de enfoque didático em diferentes disciplinas e níveis de formação. Destacam-se os estudos CTS como perspectiva teórica que orienta a maioria desses trabalhos. Quando os estudos são derivados do campo CTS, nota-se uma tendência em atribuir centralidade à compreensão do ensino das ciências como espaço de formação para a cidadania. Dessa forma, adquirem significativa recorrência as ideias de "alfabetização científica", de "letramento científico", ou mesmo expressões como "pequenos cientistas, grandes cidadãos". Cabe destacar que esses estudos não ficam circunscritos aos espaços escolares, buscam articulações com centros de pesquisa, parques e museus.

$\mathrm{Na}$ segunda categoria, "políticas curriculares e políticas tecnológicas", notamos que tais pesquisas, em geral, fundamentam-se em estudos de enfoque político, como a sociologia política, a economia política ou a avaliação de políticas públicas. Todos os estudos selecionados nessa seção abordam questões ligadas ao 
desenvolvimento do Brasil, seja no âmbito da iniciativa privada, seja nas políticas públicas. Entretanto, a característica que consideramos central nesse grupo de pesquisas, que fez com que aproximássemos políticas tão diversas, é a centralidade da crítica do Estado que as orientam. Seja em estudos ligados à gestão da inovação, seja naqueles que versam sobre a subordinação tecnológica, o Estado está sempre sendo evidenciado.

Um terceiro conjunto de estudos, também bastante diversificado, procura compreender as relações entre a ciência, a tecnologia e a educação, tomando como referência as culturas contemporâneas em seus diferentes espaços (mídias, internet, dentre outros), assim como os modos pelos quais o sujeito contemporâneo é produzido nesses espaços. Os campos científicos dos quais esses estudos derivam são a Antropologia, a Comunicação, a Educação, a Sociologia e a Psicologia. As temáticas prioritariamente desenvolvidas são: ciência e neoliberalismo, ciência e sociedade e tecnologia e educação.

Após termos sistematizado alguns sentidos contemporâneos para as relações entre educação e tecnociência, na primeira seção, e revisado as pesquisas brasileiras no campo, posteriormente, a partir deste momento apontaremos alguns pressupostos investigativos para os estudos dos currículos escolares e suas políticas na contemporaneidade. Iniciaremos a abordagem a seguir com a apresentação de alguns de documentos da UNESCO sobre a questão, mas priorizaremos um olhar sobre os documentos curriculares dirigidos ao Ensino Médio, última etapa da Educação Básica, por entendermos que eles melhor explicitam a centralidade dos saberes tecnocientíficos na educação brasileira de nosso tempo.

\section{EDUCAÇÃO E TECNOCIÊNCIA: RESSONÂNCIAS CURRICULARES}

Quando nos propomos a estabelecer algumas perspectivas investigativas no campo dos estudos curriculares, considerando as múltiplas interconexões entre educação e tecnociência acima evidenciadas, tomamos como ponto de partida as mudanças em curso nos conhecimentos escolares. Segundo a argumentação recente de Pacheco (2006), "o que mais define e caracteriza o percurso constitutivo do Currículo é o conhecimento, alfa e ômega da escola" (p. 256). Interessa-nos refletir acerca dos diferentes tensionamentos no campo dos saberes escolares, que permitem, sobretudo no Ensino Médio, uma centralidade da pauta tecnocientífica.

Ainda que os textos curriculares contemporâneos encaminhem a formação de sujeitos autônomos, críticos e criativos, precisamos colocar sob suspeita muitas dessas dimensões. Examiná-las criticamente implica em outros movimentos de análise.

O conhecimento, nas dinâmicas sociais, culturais e ideológicas que o definem, constitui a lógica da elaboração, gestão e avaliação do currículo pelo que as aprendizagens dos alunos não são meros processos técnicos mediados por indicadores de desempenho (PACHECO, 2006, p. 264). 
Pensando a produção dos currículos escolares para além de processos técnicos, mas inseridos na gramática política e econômica de nosso tempo, é que, neste momento, comporemos algumas perspectivas investigativas para o campo, situando-as a partir da documentação curricular do Ensino Médio. No que tange aos organismos internacionais, podemos observar que a educação tecnocientífica (sobretudo no Ensino Médio) tem se constituído como um dos principais campos de investimento das atividades atuais da UNESCO. O estímulo e as orientações a esse campo têm passado, em geral, por duas possibilidades de ação, ora contribuindo para o desenvolvimento econômico do País, ora desencadeando práticas que popularizem o acesso à ciência e à tecnologia como forma de despertar talentos. Em ambas as situações podemos visibilizar um intenso e produtivo entrelaçamento entre as práticas educativas e o desenvolvimento econômico. Sob essa lógica, um determinado país opta por investimentos nessa área planejando resultados futuros ou, como afirma um importante documento desse organismo internacional, realiza investimentos "à espera dos ovos de ouro" (UNESCO, 2005, p. 4).

Desde a inspiração dos recentes documentos publicados por esse organismo internacional, as políticas e práticas educativas do Estado brasileiro tendem a atribuir centralidade a uma concepção de Ensino Médio que dialogue permanentemente com as mudanças no mundo do trabalho e com as inovações tecnocientíficas. Em geral, tais publicações tendem a posicionar o conhecimento como um recurso fundamental ao desenvolvimento econômico de uma Nação na atualidade. Partem do entendimento de que um país que não prioriza a educação tende a ocupar uma posição de subalternidade no cenário da competitividade internacional, ou, ainda, que a diferenciação entre países ricos e pobres na atualidade tem como fator principal a criação e a distribuição dos benefícios do saber científico (UNESCO, 1999; UNESCO, 2003).

A condição de desigualdade no acesso ao saber científico indica que esses países, além de buscarem investimentos para a consolidação de uma matriz científico-tecnológica, devem proporcionar que esses saberes sejam garantidos a todos por meio de processos de democratização. Tal democratização implica em uma ampliação das possibilidades de acesso à ciência, desencadeando um imperativo político de "ciência para todos", expressão essa que nomeia uma importante publicação da UNESCO. Na medida em que o objetivo passa a operar no eixo da democratização, a instituição escolhida por essas políticas para desencadear tal processo é a escola, ou seja, aquela instituição com importantes serviços prestados em atividades de massa. Assim, em um artigo publicado pelo organismo internacional, intitulado "Ensino de Ciências: o futuro em risco", são enunciadas algumas das premissas políticas dessas práticas.

Se é indiscutível a importância da ciência e tecnologia para o desenvolvimento econômico e social do país, é preciso reconhecer que entre os condicionantes desse desenvolvimento estão uma educação científica de qualidade nas escolas; a formação de profissionais qualificados; a existência de universidades e instituições de pesquisas consolidadas; a integração 
entre a produção científica e tecnológica e a produção industrial; a busca de solução dos graves problemas sociais e das desigualdades (UNESCO, 2005, p. 2).

Com um prévio conjunto de investimentos, a publicação privilegia apresentar alguns dos sentidos pelos quais a educação científica nas escolas pode contribuir para o desenvolvimento econômico e social de uma determinada região. Como indica o próprio título da publicação, o grande problema está no futuro colocado em risco, ou seja, que com baixos investimentos em educação científica, o país pode ficar para trás na competitividade internacional. De forma mais enfática o texto indica que "a ineficácia dos nossos sistemas de ensino na promoção de uma educação científica de qualidade tem um custo alto para o Brasil. Por um lado, diminui-se o número de profissionais nas áreas científicas e, com isso, perde-se em posição nos mercados competidores" (UNESCO, 2005, p.4).

Em articulação à publicação desses documentos pela UNESCO, não é difícil perceber a produtividade destas inter-relações na educação nacional. Nas Orientações Curriculares para o Ensino Médio (2006), ao tratar dos conhecimentos de Biologia, mais especificamente ao explicitarem os encaminhamentos para as escolas organizarem seu projeto pedagógico, indica-se que a principal meta a ser buscada pela instituição escolar é "compreender e interpretar os impactos do desenvolvimento científico e tecnológico na sociedade e no ambiente” (BRASIL, 2006, p. 20). O documento aponta que o objetivo acima se torna fundamental devido aos avanços dos estudos em genética e a grande biodiversidade do Brasil. Ao mesmo tempo em que atribui centralidade a esses aspectos, o documento postula uma vinculação entre desenvolvimento científico e educação cidadã. "Todos devem aprender ciência como parte de sua formação cidadã, que possibilite a atuação social responsável e com discernimento diante de um mundo cada vez mais complexo" (BRASIL, 2006, p. 21).

O mesmo documento (BRASIL, 2006), ao tratar dos conhecimentos de Física, é bem mais enfático no que diz respeito aos conhecimentos tecnológicos. Ele critica os livros didáticos por estes fazerem um uso simplesmente ilustrativo da tecnologia atual. "Deve-se tratar a tecnologia como atividade humana em seus aspectos prático e social, com vistas à solução de problemas concretos" (BRASIL, 2006, p. 47). O documento evidencia como conceito delineador do ensino da disciplina no Ensino Médio a noção de "alfabetização científica e tecnológica". Tal noção objetivaria "que os alunos compreendam a predominância de aspectos técnicos e científicos na tomada de decisões sociais significativas e os conflitos gerados pela negociação política" (BRASIL, 2006, p. 47). Considerando os desafios de um mundo em permanente mudança (científicas, tecnológicas, culturais, dentre outras), as Orientações encaminham que os currículos do Ensino Médio devam primar pelo "trabalho interdisciplinar" (BRASIL, 2006, p. 90). Para tanto, é sugerido, como alternativa, o "trabalho com projetos". O trabalho com projetos, além de operar desde a resolução de problemas, promoveria interlocuções e aproximações com diferentes temáticas sociais. 
Um projeto pode favorecer a criação de estratégias de organização dos conhecimentos escolares, ao integrar os diferentes saberes disciplinares. Ele pode iniciar a partir de um problema bem particular ou de algo mais geral, de uma temática ou de um conjunto de questões inter-relacionadas. Mas, antes de tudo, deve ter como prioridade o estudo de um tema que seja de interesse dos alunos, de forma que se promova a interação social e a reflexão sobre problemas que fazem parte de sua realidade (BRASIL, 2006, p. 85).

O Relatório Pedagógico do ENEM - Exame Nacional do Ensino Médio (INEP, 2008), ao apresentar seu modelo de avaliação, argumenta que "foi desenvolvido com ênfase na aferição das estruturas mentais com as quais se constrói continuamente o conhecimento e não apenas a memória” (INEP, 2008, p. 37). O relatório justifica a escolha dessa concepção de conhecimento devido às intensas mudanças na sociedade contemporânea. Assim, o estudante deve "ser capaz de compreender o mundo em que se vive, tal é a velocidade das mudanças sociais, econômicas, tecnológicas e do próprio acervo de novos conhecimentos com os quais se convive diariamente e que invadem todas as estruturas da escola" (INEP, 2008, p. 37).

As rápidas mudanças a que estamos submetidos contemporaneamente, sobretudo as tecnocientíficas, também são utilizadas para justificar a ênfase na resolução de problemas. "Hoje, por exemplo, um conhecimento científico, uma tecnologia ensinada na escola é rapidamente substituída por outra mais moderna, mais sofisticada e atualizada, às vezes, antes mesmo que os alunos tenham percorrido um único ciclo de escolaridade" (INEP, 2008, p. 38). O documento visibiliza que tais pressupostos devem orientar não apenas a organização da avaliação em larga escala, mas também encaminhar rápidas e profundas reformas dos sistemas de ensino do Ensino Médio e nos seus modos de conceber o conhecimento escolar.

Ampliando o olhar para publicações ainda mais recentes, podemos afirmar que são essas mesmas concepções que orientam o "Programa Ensino Médio Inovador” (BRASIL, 2009), do Ministério da Educação, voltado às instituições que oferecem essa etapa da Educação Básica. Da mesma forma que os documentos anteriores, aponta a importância do Ensino Médio, uma vez que este "tem uma função estratégica para a construção de uma nação, de modo a envolver os aspectos culturais, sociais, políticos e econômicos como condição para uma relação soberana e não subalterna às demais nações" (BRASIL, 2009, p. 6). É possível notar, por esse argumento e pelas recorrências discursivas acima, o modo como, na contemporaneidade, o Ensino Médio (e o conjunto de conhecimentos e competências nele mobilizados) é posicionado de forma estratégica para a produção da Nação.

Ao enaltecer a tríade ciência/tecnologia-trabalho-cultura como organizadoras das práticas curriculares, o projeto propõe algumas dimensões para a constituição de um "currículo inovador” (BRASIL, 2009, p. 9). Esse currículo inovador tomaria como intencionalidade "erigir uma escola ativa e criadora, construída a partir de princípios que unifiquem. na pedagogia, ethos, logos e tecnos, tanto no plano metodológico quanto epistemológico" (BRASIL, 2009, p. 9). O projeto apresenta vinte e dois indicativos dessa nova configuração curricular. Apresentaremos, a seguir, dois deles, a fim de evidenciar algumas de suas especificidades: 
- Incorporar, como princípio educativo, a metodologia da problematização como instrumento à pesquisa, à curiosidade pelo inusitado e ao desenvolvimento do espírito inventivo nas práticas didáticas;

- Promover a aprendizagem criativa por um processo de sistematização dos conhecimentos elaborados como caminho pedagógico de superação à mera memorização (BRASIL, 2009, p. 9).

Seguindo o itinerário de leitura dessa documentação, assim como a composição analítica proposta para este texto, podemos imediatamente notar os modos como as relações entre os conhecimentos científicos atuais, atrelados a uma configuração específica do capitalismo contemporâneo e as políticas e práticas de escolarização, tornaram-se intensas. $\mathrm{Na}$ seleção, na organização e na distribuição de conteúdos (prerrogativas das organizações curriculares), aponta-se que se faz preciso mostrar os impactos da inovação tecnológica, compreender as dinâmicas de produção e de circulação dessas tecnologias e, principalmente, produzir novos modos de pensamento desde a presença dessas temáticas e materiais. Parte-se da perspectiva de que as escolas e seus sujeitos não serão mais os mesmos com a emergência desse novo tempo. Tais regimes apontam, ainda, que se torna necessário preparar esses sujeitos para um tempo de pensamentos em rede, de atualização permanente e de modificações culturais (científicas e tecnológicas) contínuas. Essas paisagens procuram produzir reconfigurações nas disciplinas escolares, fazendo da resolução de problemas um desafiador modo de pensamento, e dos currículos, espaços de reformas permanentes.

\section{REFERÊNCIAS BIBLIOGRÁFICAS:}

BRASIL. Orientações Curriculares para o Ensino Médio: Ciências da Natureza, matemática e suas tecnologias. Brasília: Ministério da Educação, 2006.

BRASIL. Programa Ensino Médio Inovador: documento orientador. Brasília: Ministério da Educação, 2009. DANIGNO, R. Os estudos sobre ciência, tecnologia e sociedade e a abordagem da análise de política: teoria e prática. Ciência \& Ensino, v. 1, p. 1-12, 2007.

DÍAZ, E. Entre la tecnociência y el deseo: la construcción de una epistemologia ampliada. Buenos Aires: Biblos, 2007.

FERNANDES, F. O dilema educacional brasileiro. In: PEREIRA, L.; FORACCHI, M. (orgs.). Educação e Sociedade: leituras de sociologia da educação. $13^{a}$ ed. São Paulo: Companhia Editora Nacional, 1987. p. 414-441.

FOUCAULT, M. Segurança, Território, População. São Paulo: Martins Fontes, 2008a.

FOUCAULT, M. O Nascimento da Biopolitica. São Paulo: Martins Fontes, 2008b.

FURTADO, C. Desenvolvimento e política do desenvolvimento. In: PEREIRA, L.; FORACCHI, M. (orgs.). Educação e Sociedade: leituras de sociologia da educação. $13^{a}$ ed. São Paulo: Companhia Editora Nacional, 1987. p. 370-375.

INEP. Exame Nacional do Ensino Médio (ENEM): Relatório Pedagógico 2007. Brasília: INEP, 2008. LATOUR, B. Ciência em ação: como seguir cientistas e engenheiros sociedade afora. São Paulo: Ed. Unesp, 2000.

LENOIR, T. A virtualidade na ciência: o caso das cirurgias virtuais. Episteme, Porto Alegre, v.2, n. 4, p. 73-101, 1997. 
MARCHESINI, R. Uma hermenêutica para a tecnociência. In: NEUTZLING, I.; ANDRADE, P. F. C. (Orgs.). Uma sociedade pós-humana: possibilidades e limites das nanotecnologias. São Leopoldo: Ed. Unisinos, 2009, p. 153-182.

MCT. Indicadores Nacionais de Ciència e Tecnologia (C\&T). Brasília: Ministério da Ciência e da Tecnologia, 2008. PACHECO, J. A . Uma perspectiva actual sobre a investigação em Estudos Curriculares. Perspectiva, Florianópolis, v. 24, n. 1, janeiro-junho, p. 247-272, 2006.

POSTMAN, N. Tecnopólio: a rendição da cultura à tecnologia. São Paulo: Nobel, 1994.

SANTOS, L. G. Demasiadamente pós-humano. Novos Estudos, São Paulo, n. 72, julho, p. 161-175, 2005. SANTOS, L. G. Desencontro ou "malencontro"?: os biotecnólogos brasileiros em face da sócio e da biodiversidade. Novos Estudos, São Paulo, n. 78, julho, p. 49-57, 2007.

SIBILIA, P. A tecnociência contemporânea e a ultrapassagem de limites: uma mutação antropológica. In: NEUTZLING, I.; ANDRADE, P. F. C. (Orgs.). Uma sociedade pós-bumana: possibilidades e limites das nanotecnologias. São Leopoldo: Ed. Unisinos, 2009, p. 123-140.

UNESCO. Ensino de Ciências: o futuro em risco. Edições Unesco, maio, 2005, p. 1-5.

UNESCO. A ciência para o século XXI: uma nova visão e uma base de ação. Brasília: Unesco, 2003.

UNESCO. Declaraşão sobre a ciência e o uso do conbecimento científico. Budapeste, $1^{\circ}$ de julho de 1999, 23 p. VACAREZZA, L. S. Ciencia, tecnologia y sociedad: el estado de la cuestión en América Latina. Revista Iberoamericana de Educación, Loja - Equador, n 18, p. 13-40, 1998.

WORTMANN, M. L. C.; VEIGA-NETO, A. Estudos culturais da ciência \& Educação. Belo Horizonte: Autêntica, 2001. 